\title{
A Forecast Model for the First Occurrence of Phytophthora Blight on Chili Pepper after Overwintering
}

\author{
Ki Seok Do ${ }^{1}$, Wee Soo Kang ${ }^{2}$ and Eun Woo Park ${ }^{1,3 *}$ \\ ${ }^{1}$ Department of Agricultural Biotechnology, Seoul National University, Seoul 151-921, Korea \\ ${ }^{2}$ Research Institute for Agriculture and Life Sciences, Seoul National University, Seoul 151-921, Korea \\ ${ }^{3}$ National Center for Agrometeorology, Seoul National University, Seoul 151-744, Korea \\ (Received on April 5, 2012; Revised on May 10, 2012; Accepted on May 14, 2012)
}

\begin{abstract}
An infection risk model for Phytophthora blight on chili pepper was developed to estimate the first date of disease occurrence in the field. The model consisted of three parts including estimation of zoosporangium formation, soil water content, and amount of active inoculum in soil. Daily weather data on air temperature, relative humidity and rainfall, and the soil texture data of local areas were used to estimate infection risk level that was quantified as the accumulated amount of active inoculum during the prior three days. Based on the analysis on 190 sets of weather and disease data, it was found that the threshold infection risk of 224 could be an appropriate criterion for determining the primary infection date. The $95 \%$ confidence interval for the difference between the estimated date of primary infection and the observed date of first disease occurrence was $8 \pm 3$ days. In the model validation tests, the observed dates of first disease occurrence were within the $95 \%$ confidence intervals of the estimated dates in the five out of six cases. The sensitivity analyses suggested that the model was more responsive to temperature and soil texture than relative humidity, rainfall, and transplanting date. The infection risk model could be implemented in practice to control Phytophthora blight in chili pepper fields.
\end{abstract}

Keywords : disease forecast, infection risk, pepper, Phytophthora blight, primary infection

Phytophthora blight, which is caused by Phytophthora capsici Leonian, is a devastating disease resulting in serious loss on chili pepper (Capsicum annuum Linne) yield in Korea (Hwang and Kim, 1995; Kang et al., 2011). The pathogen produces both sexual and asexual spores, which are oospores and zoospores, respectively. Oospores can germinate by formation of either a germ tube or a zoo-

\footnotetext{
*Corresponding author.

Phone) +82-2-880-4672, FAX) +82-2-872-2317

E-mail)ewpark@snu.ac.kr
}

sporangium (Ristaino and Johnston, 1999). Zoospores which are released from zoosporangia can move under saturated soil conditions and infect roots or aerial parts of plants (Duniway, 1976; Duniway, 1979). Zoosporangia may germinate directly via formation of one to several germ tubes or release 20 to 40 biflagellate motile zoospores (Hausbeck and Lamour, 2004). In pot tests, about 41 oospores per gram of soil and 25 zoospores per plant caused death of $50 \%$ and $95 \%$ of the plants exposed under flooded soil condition, respectively (Bowers and Mitchell, 1991). When susceptible plants were inoculated with $2 \times 10^{5}$ zoospores of the pathogen per plant by using the soil-drench method at the first-branched flowering stage of pepper in greenhouse, the incubation period of the disease was seven days (Kim et al., 1989). When susceptible plants were inoculated with $1 \times 10^{5}$ zoospores per plant in chili pepper fields by using the soil-drench method, it took five or six days until symptoms of Phytophthora blight appeared on 9-weeksgrown seedlings of chili peppers (Kim et al., 2008; Sang et al., 2008).

Various environmental factors such as temperature and soil water condition affect Phytophthora blight occurrence. Temperature has strong influence on the initiation of the disease occurrence by affecting not only growth of the pathogen, but also development of pepper plants, of which susceptibility to Phytophthora capsici changes over developmental stages of peppers (Caf-Filho and Duniway, 1995; Kim et al., 1985). Temperature influences differentiation of zoosporangia of Phytophthora spp. In the case of Phytophthora infestans, the differentiation of zoosporangia into zoospores predominated at about $12{ }^{\circ} \mathrm{C}$ while the direct germination was prevalent at $24^{\circ} \mathrm{C}$ (Erwin and Ribeiro, 1996). In general, this phenomenon applies to all species of Phytophthora, although some species produce zoospores at higher temperatures. In the case of Phytophthora capsici, the differentiation of zoosporangia into zoospores predominated at 10 to $24^{\circ} \mathrm{C}$ (Katsura, 1971). It was also reported that less than $50 \%$ of zoosporangia in soil produced zoospores at 22 to $24^{\circ} \mathrm{C}$ in the case of Phytophthora capsici 
(Bernhardt and Grogan, 1982).

Rainfall, irrigation, topsoil texture and drainage have direct influence on soil water content, which is a critical factor affecting disease incidence of Phytophthora blight on chili pepper plants (Hwang and Kim, 1995). Soil water content, especially the matric potential of soil water, is important in mycelia growth, production of zoosporangia, direct germination of zoosporangia, zoospore release, and zoospore movement of Phytophthora capsici (Erwin et al., 1983; Kreutzer et al., 1940; Ristaino and Johnston, 1999). Different stages in the life cycle of Phytophthora spp. show different responses to soil water matric potential. The matric potential of approximately $-3,000 \mathrm{kPa}$ is the lower limit for mycelial growth, $-500 \mathrm{kPa}$ for production of zoosporangia, and $-350 \sim-5 \mathrm{kPa}$ for zoospore release of the pathogen on soil surface (Erwin et al., 1983). The lower limits of soil water matric potential for zoosporangia production on the inoculum buried under 5 to $20 \mathrm{~cm}$ of soil are lower than those in the case of inoculum on soil surface. Especially, most of the root-infecting Phytophthora spp. are able to produce zoosporangia only in free water or in aqueous salt solutions and soil extract (Erwin and Ribeiro, 1996). Direct germination by zoosporangia of Phytophthora drechsleri was observed at soil water matric potential levels down to $-300 \mathrm{kPa}$ (Duniway, 1975). Soil water content also influences the germination of oospores, which is considered as the primary overwintering propagules in the field (Bowers et al., 1990; Hord and Ristaino, 1992). A period of soil saturation is required for oospores germination of $P$. capsici, but oospore germination does not frequently occur under constant saturation of soil water (Bowers and Mitchell, 1990; Hord and Ristaino, 1992).

The survival of Phytophthora capsici in soil varies depending on environmental conditions and the existing types of inoculum such as mycelia, oospores, zoosporangia, and zoospores. Oospore could survive for 6-10 months, but their viability in overwintering tests declined from $67 \%$ to 8-9\% after 27 weeks (Bowers et al., 1990). Mycelia of the pathogen remained viable for 120 days in soil (Erwin and Ribeiro, 1996). In summer, zoosporangia were able to survive for 4 to 8 weeks (Bowers et al., 1990; Erwin and Ribeiro, 1996). In contact with chili pepper roots, the density of zoospores of Phytophthora capsici became gradually decreased due to germination during 48 hours after the contact and consequently small amounts of zoospores remained (Hur, 2002). In contrast, the number of zoospores was not decreased significantly during at least $48 \mathrm{hr}$ without contact with chili pepper roots. These results indicate that the zoospores in the suspension could survive and remain infectious at least for 2 days after release from zoosporangia regardless of contact with host plant roots.

Fungicide application is an effective control strategy against Phytophthora blight (Jee et al., 2000; Ristaino and Johnston, 1999). However, it is not easy to spray fungicides to control the disease when long rainy periods occur in the field as the case of summer in Korea. Consequently, pepper growers in Korea often need to protect their crop from becoming infected by the primary inoculum of Phytophthora capsici after overwintering. Forecast information on possible occurrence of the disease after overwintering would be useful for pepper growers to implement effective control strategies against the disease.

A forecasting model for estimating Phytophthora blight incidence in chili pepper, PEPBLIGHT, was developed in Korea (Hwang and Lee, 2001). The PEPBLIGHT is a linear regression model describing the quantitative relationship between weather factors and Phytophthora blight incidence at two chili pepper fields in Andong during 1997-1998. It was attempted to predict the initiation and progress of the disease using the sum of rainy hours, the accumulated hours of $100 \%$ relative humidity, and degree-days of soil temperature accumulated during the past 40 days with the base temperature of $21^{\circ} \mathrm{C}$. However, PEPBLIGHT has never been evaluated for its accuracy in predicting the disease development. Besides, PEPBLIGHT is an empirical model developed based on the weather and disease data from a specific location so that it may not be appropriate to apply for different locations.

The present study was conducted (1) to develop a new model for estimating the infection risk level of Phytophthora blight considering not only weather factors but also soil water content; and (2) to predict the date of first occurrence of the disease after overwintering based on the estimated infection risk levels.

\section{Materials and Methods}

Effect of temperature on zoosporangium production. An isolate (P-20156) of Phytophthora capsici was obtained from the National Institute of Agricultural Science and Technology (NIAST), Rural Development Administration, Suwon, Korea. The isolate was grown on the $10 \%$ V8 juice agar medium (100 $\mathrm{ml}$ of V8 juice, $900 \mathrm{ml}$ of distilled water, $1 \mathrm{~g}$ of $\mathrm{CaCO}_{3}, 17 \mathrm{~g}$ of agar/l) at $25^{\circ} \mathrm{C}$ under dark conditions for 60 hours. Then, the agar pieces of $18 \times 18 \mathrm{~mm}^{2}$ were removed from the margins of the colonies. The agar pieces were cultured in the Jee's antimicrobial solution (1 $\mathrm{mg}$ of rifampicin, $10 \mathrm{mg}$ of ampicillin, $2.5 \mathrm{mg}$ of hymexazol, $5 \mathrm{mg}$ of pentachloronitrobenzene/l) (Jee et al., 2000) at 15, $22,25,27,32$, and $35^{\circ} \mathrm{C}$. The cultures were kept under light conditions for $48 \mathrm{~h}$. The zoosporangia formed from the mycelial mats on the surface $\left(18 \times 18 \mathrm{~mm}^{2}\right)$ of five agar pieces for each temperature were examined by mounting the agar pieces on a microscope (Axioplan 2, Carl Zeiss, 
Germany) with a $10 \times$ objective lens. The agar medium and the other components used in the experiments except for the Jee's antimicrobial solution were autoclaved for 15 minutes at $121^{\circ} \mathrm{C}$. The Jee's antimicrobial solution was sterilized by filtration through $0.22 \mu \mathrm{m}$ membrane (Corning Inc., USA). The number of zoosporangia produced at each temperature was transformed using the common logarithm and then linear regression analysis was applied to determine quantitative relationship between zoosporangium production and temperature using the General Linear Model Procedure of SAS (SAS Institute Inc., 2011b).

Estimation of the daily mean soil temperature under polyethylene film mulching. Since most chili peppers are grown on beds mulched with polyethylene film in Korea, the daily mean soil temperature under polyethylene film at chili pepper fields is needed for estimating the number of the zoosporangia produced in soil. Ambient air and soil temperatures were monitored at chili pepper fields mulched with polyethylene film in Suwon from June 2 to September 30, 2006 and in Asan from April 1 to September 30, 2006 using automated weather stations (AWS) (Campbell Scientific, Inc., USA) with CR10X data logger and air and soil temperature sensors (HMP45C and 107-L, respectively). The air and soil temperature sensors were installed at 120 $\mathrm{cm}$ above ground and $30 \mathrm{~cm}$ below ground in the chili pepper fields, respectively. The data from Suwon and Asan were pooled together, and a total of 303 data sets were analyzed by linear regression analysis to determine quantitative relationship between daily mean air and soil temperatures in the chili pepper fields with polyethylene film mulching using the General Linear Model Procedure of SAS (SAS Institute Inc., 2011b).

Estimation of volumetric soil water content. A model for estimating volumetric soil water content was developed based on the water balance equation (Hasegawa et al., 2006; Jung et al., 2000):

$$
\Delta \mathrm{W}=(\mathrm{P}+\mathrm{I}+\mathrm{U})-(\mathrm{R}+\mathrm{D}+\mathrm{E})
$$

where $\Delta \mathrm{W}$ is the water balance in soil; and $\mathrm{P}, \mathrm{I}, \mathrm{U}, \mathrm{R}, \mathrm{D}$ and $\mathrm{E}$ are the amount of water due to precipitation, irrigation, upward movement by capillary force, runoff, drainage by gravity, and evapotranspiration, respectively.

Considering the cultural practices that are commonly applied by pepper growers in Korea, following assumptions were made to simplify eq. 1: (1) Irrigation is performed one time immediately after transplanting pepper seedlings in the field and no additional irrigation is made during the growing period; (2) chili pepper fields in Korea are generally well-drained; and (3) upward movement of water due to capillary force is ignorable. With the assumptions, the daily water balance $\left(\Delta \mathrm{W}_{\mathrm{n}}\right)$ at day $\mathrm{n}$ could be written as:

$$
\Delta \mathrm{W}_{\mathrm{n}}=\mathrm{P}_{\mathrm{n}}-\left(\mathrm{R}_{\mathrm{n}}+\mathrm{D}_{\mathrm{n}}+\mathrm{E}_{\mathrm{n}}\right)
$$

In eq. $2, R_{n}$ can be estimated using the runoff model that was developed by the U.S. National Resources Conservation Service (NRCS model, hereafter) (Cronshey et al., 1986; Ponce and Hawkins, 1996). The NRCS model simulates the rainfall-runoff relationship of small watershed considering soil texture, drainage, land use, and antecedent soil moisture condition. Using the NRCS model, the daily runoff $\left(R_{n}\right)$ at day $n$ is calculated as follows:

$$
\mathrm{R}_{\mathrm{n}}=\left(\mathrm{P}_{\mathrm{n}}-0.2 \mathrm{~S}\right)^{2} /\left(\mathrm{P}_{\mathrm{n}}+0.8 \mathrm{~S}\right)
$$

where $P_{n}$ is the precipitation at day $n$, and $S$ is the maximum potential retention of water. $\mathrm{S}$ is a reciprocal function of the runoff curve number that is determined by antecedent rainfall during the prior five days, drainage and land use. The case of straight row, good hydrologic condition, and hydrologic soil group B in the NRCS model was applied for drainage and land use in this study.

Assuming that chili pepper fields in Korea are generally well-drained, drainage is accounted for in the water balance model only after rainfall which makes soil water content more than the field capacity. Otherwise, $D_{n}$ is considered to be zero in eq. 2 .

Evapotranspiration $\left(E_{n}\right)$ in eq. 2 was estimated by combining the crop coefficient of chili pepper and the reference evapotranspiration by multiplication (Allen et al., 1998; Jung et al., 2000):

$$
\mathrm{E}_{\mathrm{n}}=\mathrm{Kc}_{\mathrm{n}} \times \mathrm{RET}_{\mathrm{n}}
$$

where $\mathrm{Kc}_{\mathrm{n}}$ and $\mathrm{RET}_{\mathrm{n}}$ are the crop coefficient of chili pepper and the reference evapotranspiration at day $\mathrm{n}$, respectively.

The reference evapotranspiration (RET) is the evapotranspiration that could occur under well-watered conditions from the reference surface of a hypothetical grass crop with an assumed crop height of $12 \mathrm{~cm}$, a fixed surface resistance of $70 \mathrm{~s} / \mathrm{m}$, and an albedo of 0.23 (Allen et al., 1998). In this study, $\mathrm{RET}_{\mathrm{n}}$ was estimated by a humidity method using daily mean air temperature and relative humidity (Singh, 1988). The crop coefficient $\left(\mathrm{Kc}_{\mathrm{n}}\right)$ is simply the ratio of evapotranspiration observed for the crop studied over that observed for the reference crop under the same conditions (Allen et al., 1998). In this study, $\mathrm{Kc}_{\mathrm{n}}$ for chili pepper was estimated by a model which was developed based on the basal crop coefficient of chili pepper, and soil water content (Jung, 2005). Jung (2005) made intensive measurement on crop growth, soil water, and meteorological factors for chili pepper at three locations in Korea during the growth periods in 1988-1990 and calculated the basal crop coefficients of chili pepper at 5-day intervals over the growth periods at Suwon, Daegu, and Cheongju. 
The average values of basal crop coefficients for the three locations were used to calculate $\mathrm{Kc}_{\mathrm{n}}$ in this study.

Using the modified water balance model (eq. 2), daily soil water content can be obtained by the following equation:

$$
\mathrm{WC}_{\mathrm{n}}=\mathrm{WC}_{\mathrm{n}-1}+\frac{\Delta \mathrm{W}_{\mathrm{n}}}{\mathrm{DT}}
$$

where $\mathrm{WC}_{\mathrm{n}}$ is the volumetric water content of soil at day $\mathrm{n}$, and DT is the depth of topsoil. Since chili pepper is known to have root systems mainly distributed in the topsoil of 30 cm depth (Jee et al., 2000), DT was set to $300 \mathrm{~mm}$ in this study. Consequently, eq. 5 can be expressed as follows:

$$
\begin{aligned}
\mathrm{WC}_{\mathrm{n}} & =\mathrm{WC}_{\mathrm{n}-1}+\frac{\mathrm{P}_{\mathrm{n}}-\left(\mathrm{R}_{\mathrm{n}}+\mathrm{D}_{\mathrm{n}}+\mathrm{E}_{\mathrm{n}}\right)}{300} \\
& =\mathrm{WC}_{0}+\frac{1}{300} \sum_{1}^{\mathrm{n}}\left(\mathrm{P}_{\mathrm{k}}-\mathrm{R}_{\mathrm{k}}-\mathrm{D}_{\mathrm{k}}-\mathrm{E}_{\mathrm{k}}\right)
\end{aligned}
$$

where $\mathrm{WC}_{0}$ is the volumetric water content of soil at the transplanting date of pepper seedlings. Assuming that sufficient amount of water is supplied to chili pepper fields at transplanting, $\mathrm{WC}_{0}$ is set to the field capacity, which varies depending upon soil texture. The soil texture data used in this study were obtained from the digital soil map of Korea at the spatial resolution of $30 \mathrm{~m} \times 30 \mathrm{~m}$ (Hong et al., 2009).

The accuracy of the soil water content estimation was evaluated using the weather data collected at two chili pepper fields in Suwon and Andong during April 26 to August 30, 2008. The soil textures of the chili pepper fields at Suwon and Andong were loam and sandy loam, respectively. The AWS's with CR10X data logger were installed at the chili pepper fields and equipped with sensors to monitor air temperature $\left({ }^{\circ} \mathrm{C}\right)$ and relative humidity $(\%)$ (HMP45C), rainfall (mm) (TE525MM), soil temperature $\left({ }^{\circ} \mathrm{C}\right)(107)$, soil water contents $\left(\mathrm{m}^{3} / \mathrm{m}^{3}\right)(\mathrm{CS} 616)$, and solar radiation $\left(\mathrm{MJ} / \mathrm{m}^{2}\right)(\mathrm{LI} 200 \mathrm{X})$.

Infection risk model. Referring to the research results which were already published in the literature, following assumptions were made to consider the behavior of zoosporangia and zoospores in soil: (1) the zoosporangia can be produced at $>-3,000 \mathrm{kPa}$ of soil water matric potential (Erwin et al., 1983); (2) a zoosporangium germinates directly or releases 20 zoospores at $>-500 \mathrm{kPa}$ of soil water matric potential (Duniway, 1975; Erwin et al., 1983; Hausbeck and Lamour, 2004); (3) the zoospores or germinated zoosporangia can survive and initiate infection for 3 days (Hur, 2002); and (4) the proportion of zoosporangia (p) that are going to release zoospores is determined by daily mean soil temperature (Ts) at $30 \mathrm{~cm}$ depth under the polyethylene film mulching at chili pepper fields and $\mathrm{p}$ can be determined as the following equation (Bernhardt and
Grogan, 1982; Erwin and Ribeiro, 1996; Katsura, 1971):

$$
\begin{aligned}
& \mathrm{p}=-0.1 \mathrm{Ts}+2.5 \text { when } 15 \leq \mathrm{Ts} \leq 25 \\
& \mathrm{p}=1 \text { when Ts }<15 \\
& \mathrm{p}=0 \text { when Ts }>25
\end{aligned}
$$

Since most of root-infecting Phytophthora spp. produce zoosporangia only in free water or in aqueous salt solutions and soil extract (Erwin and Ribeiro, 1996), the number of zoosporangia $\left(\mathrm{PZ}_{\mathrm{n}}\right)$ produced at day $\mathrm{n}$ in an arbitrary volume of soil of which the soil water matric potential is higher than $-3,000 \mathrm{kPa}$ can be estimated as follows:

$$
\mathrm{PZ}_{\mathrm{n}}=\mathrm{Zmax}_{\mathrm{n}} \cdot \mathrm{WC}_{\mathrm{n}}
$$

where $\mathrm{Zmax}_{\mathrm{n}}$ is the maximum number of zoosporangia that can be produced at day $n$. The $Z \max _{n}$ is a temperaturedependent variable that is estimated by the empirical model developed in this study. The $\mathrm{WC}_{\mathrm{n}}$ is the volumetric soil water content at day $\mathrm{n}$, which is estimated by eq. 6 . When the soil water matric potential is lower than $-3,000 \mathrm{kPa}, \mathrm{PZ}_{\mathrm{n}}$ is zero. The $\mathrm{PZ}_{\mathrm{n}}$ is accumulated until the soil water matric potential becomes higher than $-500 \mathrm{kPa}$ at which the accumulated zoosporangia germinate directly or release zoospores. The soil water contents in matric potential for specific soil textures was calculated from the volumetric soil water content that was estimated by eq. 6 using the quantitative relationship between the soil water matric potential and the volumetric soil water content (Campbell, 1985; Shiozawa and Campbell, 1991).

Since the forms of active inoculum which can infect the host plants are mainly zoospores and germinated zoosporangia (Erwin et al., 1983; Jee et al., 2000), the amount of the active inoculum $\left(\mathrm{AI}_{\mathrm{n}}\right)$ which is produced at day $n$ is the sum of the amount of zoospores and germinated zoosporangia at day $\mathrm{n}$. It can be calculated as follows:

$$
\mathrm{AI}_{\mathrm{n}}=20 \cdot \mathrm{p} \cdot \mathrm{Z}_{\mathrm{n}}+(1-\mathrm{p}) \cdot \mathrm{Z}_{\mathrm{n}}=(19 \mathrm{p}+1) \cdot \mathrm{Z}_{\mathrm{n}} \quad \text { [eq. 9] }
$$

where $\mathrm{p}$ is the proportion of zoosporangia which release zoospores and $\mathrm{Z}_{\mathrm{n}}$ is the total number of accumulated zoosporangia at day $n$.

Assuming that the zoospores and germinated zoosporangia are able to survive and initiate infections for three days, the infection risk (IR) of Phytophthora blight can be estimated as the amount of active inoculum accumulated for three days. Consequently, the infection risk of Phytophthora blight at day $\mathrm{n}\left(\mathrm{IR}_{\mathrm{n}}\right)$ can be calculated as follows:

$$
\mathrm{IR}_{\mathrm{n}}=\Sigma_{\mathrm{n}-2}^{\mathrm{n}} \mathrm{AI}_{\mathrm{k}}=\Sigma_{\mathrm{n}-2}^{\mathrm{n}}(19 \mathrm{p}+1) \mathrm{Z}_{\mathrm{k}}
$$

Threshold of infection risk. In order to determine a threshold level of infection risk that may be high enough to cause infections on pepper plants in the field, the estimated daily infection risks $\left(\operatorname{IR}_{n}\right)$ at 156 locations during the pepper 
growing seasons in 2001-2006 were calculated using the infection risk model (eq. 10). One hundred and ninety data sets from 156 locations were included in the analysis. The estimated daily infection risks were analyzed with reference to the dates of first occurrence of Phytophthora blight at the corresponding locations each year. Weather data and soil texture data used for estimating the infection risks were obtained from the Korea Meteorological Administration (KMA) and NIAST, respectively. The weather data were collected by AWS's located within less than $15 \mathrm{~km}$ distance from the pepper fields for disease survey. Air temperatures at the location of field plots were estimated from the observed temperatures at three neighboring weather stations by the inverse squared distance weighting (IDW) method with consideration of air temperature decrement as elevation increases (Yun et al., 1999) and the other weather data that are needed for estimating the infection risk were collected from the nearest weather station to each pepper field for disease survey. The estimated dates of first occurrence of Phytophthora blight after overwintering at each location in each year were determined based on the estimated infection risks as the threshold level of estimated infection risk varied from 1 to 500. The observed dates of first occurrence of the disease at 156 locations during 2001-2006 were obtained from RDA and seven Provincial Agricultural Research and Extension Services in Gyeonggi-do, Gangwon-do, Chungcheongbuk-do, Chungcheongnam-do, Jeollabuk-do, Jeollanam-do, and Gyeongsangbuk-do.

Differences in days (DIF, hereafter) between the estimated dates of primary infection and the observed dates of first disease occurrence were obtained for 190 data sets. The mean and standard deviation of DIF were calculated as the threshold level of daily infection risk increased from 1 to 500. Considering the mean and standard deviation of DIF and the number of data sets included in the analysis, the optimum level of the threshold infection risk was determined. The 190 values of DIF were classified by 10-day intervals and the frequency distribution of all classes was tested for normality by the Shapiro-Wilk test (Shapiro and Wilk, 1965) using the Univariate Procedure of SAS (SAS Institute Inc., 2011a). Finally, the date of first disease occurrence after overwintering was estimated based on the optimum threshold level of estimated daily infect risk and the mean of DIF.

Validation of estimating the dates of first disease occurrence. Accuracy in estimating the first date of disease occurrence by the infection risk model was evaluated by comparing the estimated and the observed dates of first disease occurrence after overwintering using the weather and disease data collected from six chili pepper fields at Suwon during 2007-2009, Hwaseong in 2008, Bonghwa in
2009 , and Taean in 2009. Hourly weather conditions of the chili pepper fields were monitored by automated weather stations with the same configuration as described previously. Disease occurrence of Phytophthora blight was carefully examined in the chili pepper fields at 6 or 7-day intervals from May 1 until the first appearance of diseased plants.

Sensitivity of the infection risk model. Using the weather and soil data collected at the chili pepper field at Suwon in 2008 as the reference data, the sensitivity of the infection risk model (eq. 10) was analyzed against five variables including soil texture, daily mean temperature, daily mean relative humidity, daily rainfall and transplanting date. By changing values of a variable in the model with other variables being the same as the reference data, responses of the model were analyzed. For the analysis, transplanting dates being April 11, April 21, May 1, May 11, and May 21, and soil texture being sand, loamy sand, loam, clay loam and clay were substituted in the model. In the case of daily mean temperature and daily mean relative humidity, values being $\pm 1{ }^{\circ} \mathrm{C}$ and $\pm 2{ }^{\circ} \mathrm{C}$, and $\pm 10 \%$ and $\pm 20 \%$ from the reference temperature and humidity, respectively, were used for the model testing. As for daily rainfall, $\pm 30 \%$ and $\pm 50 \%$ of the reference daily rainfall were applied to the model.

\section{Results}

Effect of temperature on zoosporangium production. Zoosporangia of Phytophthora capsici were produced on the surface of the $10 \%$ V8 juice agar medium in the Jee's antimicrobial solution at $15-32^{\circ} \mathrm{C}$ and were not observed at $35^{\circ} \mathrm{C}$ (Fig. 1). The optimum temperature for zoosporangium production was approximately $25^{\circ} \mathrm{C}$. The linear regression analysis resulted in the $2^{\text {nd }}$ order polynomial equation:

$$
\log _{10}(Z \max +1)=-9.0825+0.8674 \mathrm{~T}-0.0173 \mathrm{~T}^{2}
$$

$\left(15 \leq \mathrm{T} \leq 35^{\circ} \mathrm{C}\right)$

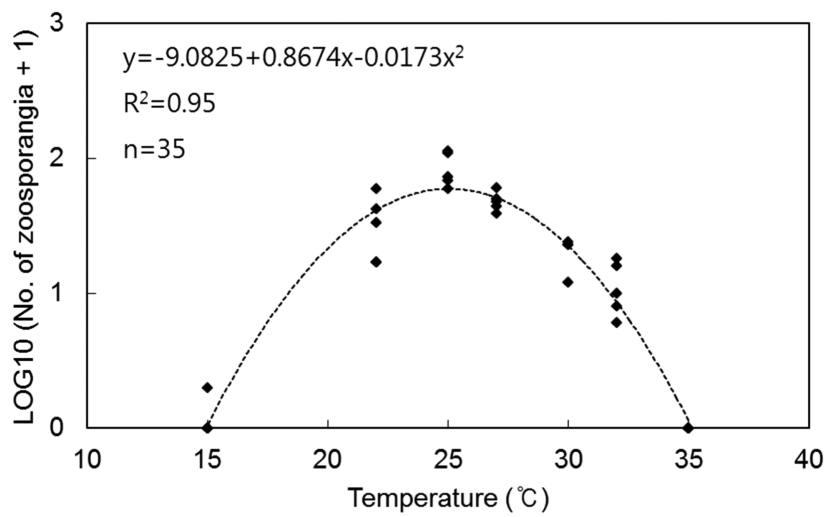

Fig. 1. Zoosporangium production of Phytophthora capsici at different temperatures. 


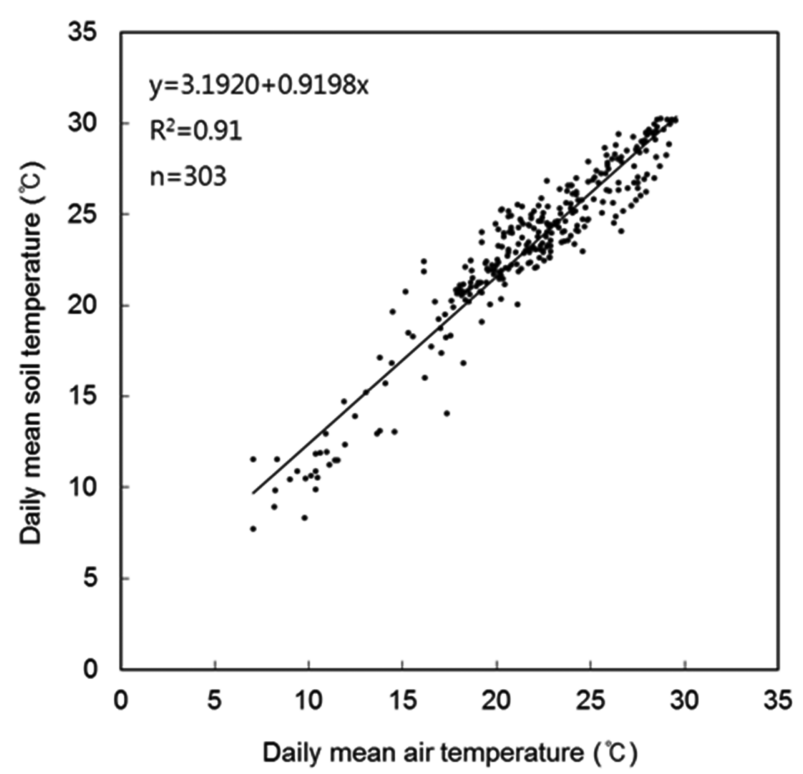

Fig. 2. Relationship between daily mean air temperature at 120 $\mathrm{cm}$ above ground and the daily mean soil temperature at $30 \mathrm{~cm}$ depth below the top of raised beds covered with polyethylene film mulching at the two chili pepper fields in Suwon during July 2 to September 30, 2006 and in Asan during April 1 to September 30, 2006. The data from Suwon and Asan were pooled together for analysis.

where $\mathrm{Zmax}$ is the number of the zoosporangia produced when temperature $(\mathrm{T})$ is within the range of $15-35^{\circ} \mathrm{C}$. The coefficient of determination $\left(\mathrm{R}^{2}\right)$ was 0.95 , indicating $95 \%$ of variation in log-transformed number of zoosporangia was accounted for by temperature.

Estimation of soil temperature and water content. Daily mean soil temperature at $30 \mathrm{~cm}$ depth under polyethylene film mulching was positively correlated with daily mean air temperature (Fig. 2). The regression equation in Fig. 2 indicated that $91 \%$ of variation in the daily mean soil temperature was accounted for by the daily mean air temperature.

Temporal changes in estimated daily soil water contents at the chili pepper fields in Suwon and Andong were compared with the observed soil water contents (Fig. 3). In general, the model (eq. 6) underestimated soil water contents although the trends of changes in estimated soil water contents over time were similar to those in the observed at both fields. Sudden increases in the estimated soil water content were noticed after each rainfall.

Threshold of infection risk. The means and standard deviations of DIF were plotted as the threshold level of estimated infection risk varied from 1 to 500 (Fig. 4). The number of data sets that were used in the calculation of mean and standard deviation were also plotted in the graph. When the threshold of infection risk was less than 322 , the

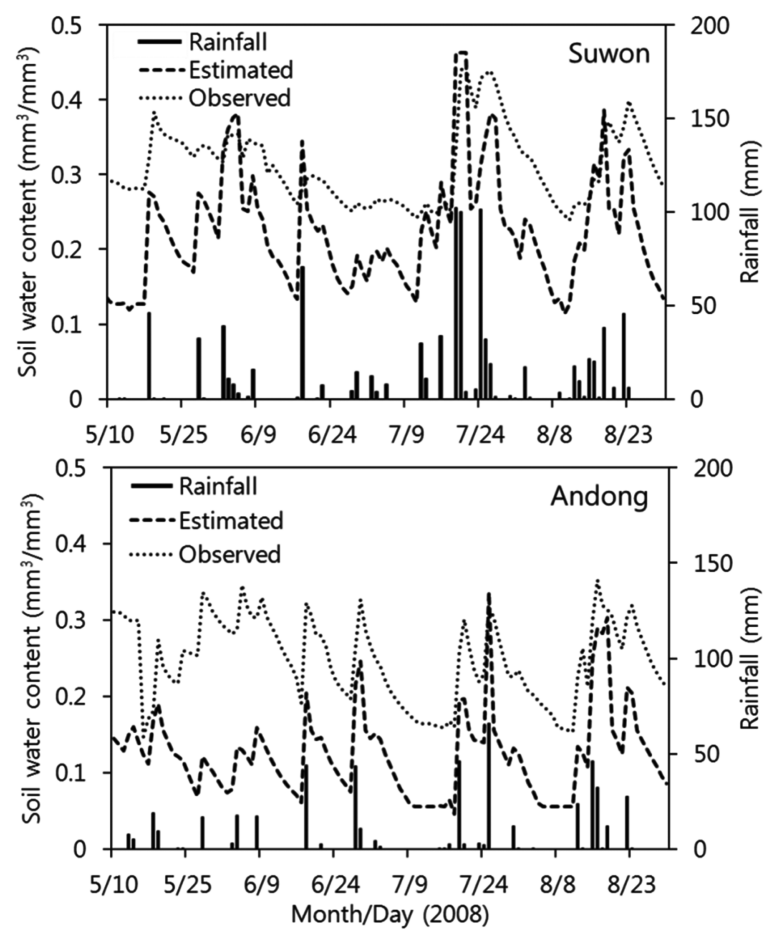

Fig. 3. Soil water contents estimated by the soil water content model (eq. 6) as compared with the observed soil water contents at Suwon and Andong in 2008. Daily rainfall is shown in histogram.

primary infection to cause the first disease occurrence after overwintering was expected to occur earlier than the observed date of actual occurrence of disease. As the threshold increased beyond 322, the mean of DIF became within the range of \pm 2 days. The standard deviation of DIF increased from 17.16 to 30.06 as the threshold level of infection risk increased. All of 190 data sets were used in the calculation of the mean and standard deviation of DIF when the threshold level was less than or equal to 224 . When the threshold level was greater than 224 , some data sets were excluded in the calculation because the estimated infection risks throughout the growing season had never been higher than the threshold infection risk in some cases. More and more data sets were excluded in the calculation as the threshold infection risk increased beyond 224 .

Considering the number of data sets included in the calculation, the infection risk level of 224 was used as the threshold level that may be high enough for the pathogen to cause infections on pepper plants in the field. With the threshold infection risk of 224, the frequency distribution of DIF showed an unimodal appearance (Fig. 5). The ShapiroWilk test resulted in the p-value of 0.139 , indicating that DIF's came from a normally distributed population at the $5 \%$ significance level. When the threshold infection risk was 224, the mean and standard deviation of DIF were -8.174 and 21.585 , respectively. Using the $t_{0.025,189}$ of 


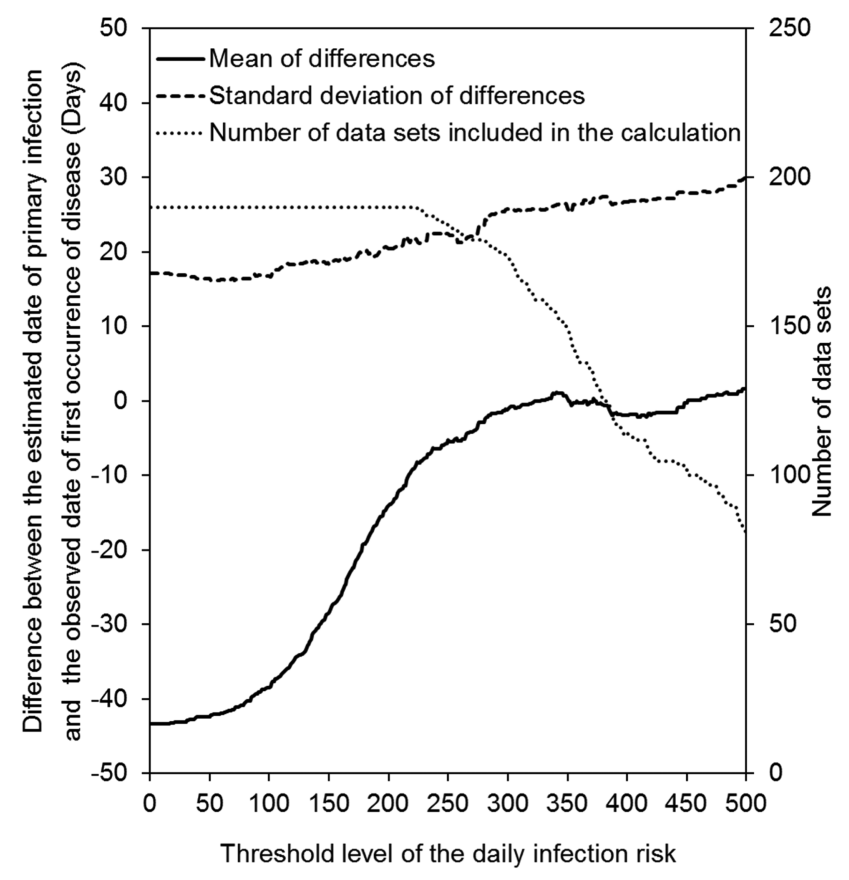

Fig. 4. The mean and standard deviation of the differences between the estimated date of primary infection and the observed date of first occurrence of Phytophthora blight after overwintering in the field as the threshold level of estimated daily infection risk was varied from 1 to 500 . The number of data sets included in the calculation of the mean and standard deviation were also plotted in the graph. One hundred and ninety data sets obtained from 156 locations of chili pepper fields during 2001-2006 were used in the analysis.

Student's $t$-distribution (Rohlf and Sokal, 1969), the 95\% confidence limits of DIF was calculated to be -11.24 -5.10 days. The result means that the incubation period between the primary infection and the first disease appearance is expected to be approximately $8 \pm 3$ days.

Validation of estimating the dates of first disease occurr-

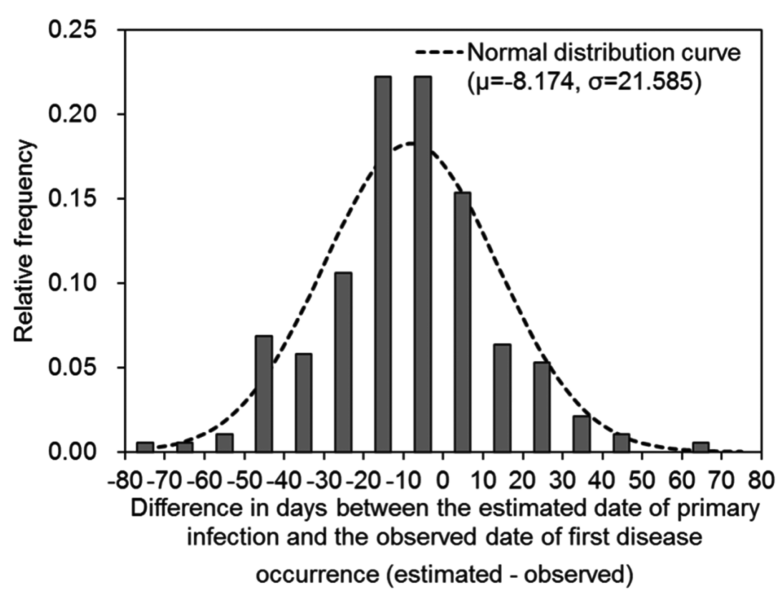

Fig. 5. Relative frequency distribution of differences in days between the estimated date of primary infection and the observed date of first occurrence of Phytophthora blight after overwintering when the threshold infection risk was 224 . One hundred and ninety data sets obtained from 156 locations of chili pepper fields during 2001-2006 were used in the analysis. The difference between the estimated and the observed dates were classified at 10-day intervals.

ence. Using the infection risk model (eq. 10) with the threshold infection risk of 224, the expected dates of primary infection were determined for the chili pepper fields at Suwon (2007-2009), Hwaseong (2008), and Taean (2009) (Table 1). As for the field at Bonghwa (2009), the estimated daily infection risk had never been 224 or more throughout the growing season and the primary infection was assumed to occur when the infection risk reached a peak of 206.4 on June 12 . The incubation period of $8 \pm 3$ days was applied to determine the expected dates of first disease occurrence. In Table 1, the estimated dates of primary infection and first disease occurrence were presented as compared with the observed dates of disease occurrence for the first time after overwintering at the monitoring field

Table 1. The estimated dates of primary infection and first occurrence of Phytophthora blight after overwintering as compared with the observed dates of first disease occurrence at the disease monitoring fields of chili pepper ${ }^{\mathrm{a}}$

\begin{tabular}{|c|c|c|c|c|}
\hline \multirow{2}{*}{ Location } & \multirow{2}{*}{ Year } & \multicolumn{2}{|c|}{ Date of first disease occurrence } & \multirow{2}{*}{$\begin{array}{l}\text { Estimated date of } \\
\text { primary infection }\end{array}$} \\
\hline & & Observed & Estimated $^{\mathrm{b}}$ & \\
\hline \multirow{3}{*}{ Suwon } & 2007 & July 3 & July 2 (June 29 July 5) & June 24 \\
\hline & 2008 & June 11 & June 11 (June 8 June 14) & June 3 \\
\hline & 2009 & June 18 & June 19 (June 16 June 22) & June 11 \\
\hline Hwaseong & 2008 & June 13 & June 11 (June 8 June 14) & June 3 \\
\hline Bonghwa $^{c}$ & 2009 & June 24 & June 20 (June 17 June 23) & June 12 \\
\hline Taean & 2009 & June 29 & July 1 (June 28 July 4) & June 23 \\
\hline
\end{tabular}

\footnotetext{
${ }^{a}$ The threshold infection risk was 224 to determine the estimated dates of primary infection by the infection risk model.

${ }^{\text {b }}$ The $95 \%$ confidence intervals for the estimated dates are in parentheses.

${ }^{\mathrm{c}}$ The primary infection was assumed to occur when the infection risk reached a peak of 206.4 on June 12 . The estimated infection risk had never been 224 or higher throughout the growing season at Bonghwa in 2009.
} 
plots. The estimated dates of first disease occurrence were within the range of \pm 2 days from the observed dates except for the field at Bonghwa in 2009. In all cases but Bonghwa, the observed dates remained within the $95 \%$ confidence intervals of the estimated dates of first disease occurrence. In the case of Bonghwa, the expected date of first disease occurrence was June 20, which was four days earlier than the observed date of first disease occurrence.

Sensitivity of the infection risk model. The reference weather conditions monitored at the chili pepper field in Suwon in 2008 were shown in Fig. 6. The weather condition was relatively dry in May. Responses of the infection risk model (eq. 10) to soil texture, ambient temperature and relative humidity, rainfall and transplanting date were

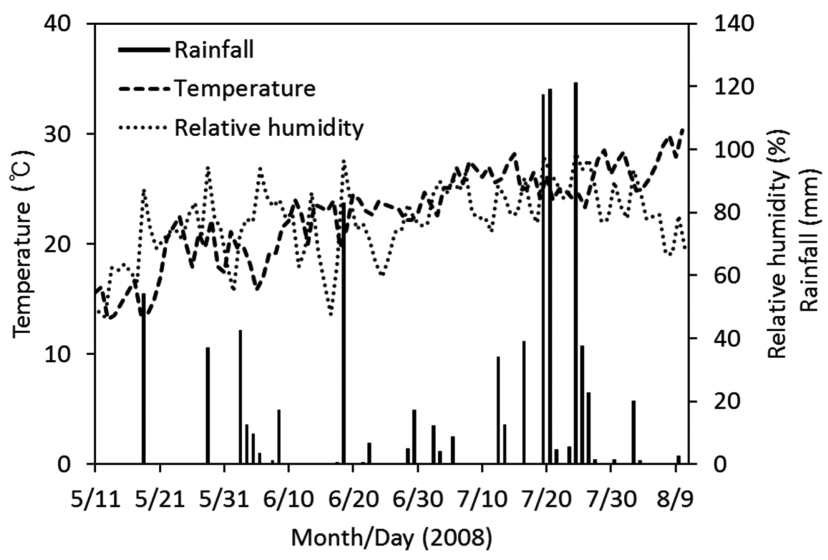

Fig. 6. Daily mean air temperature, relative humidity and rainfall monitored at the chili pepper field in Suwon in 2008.
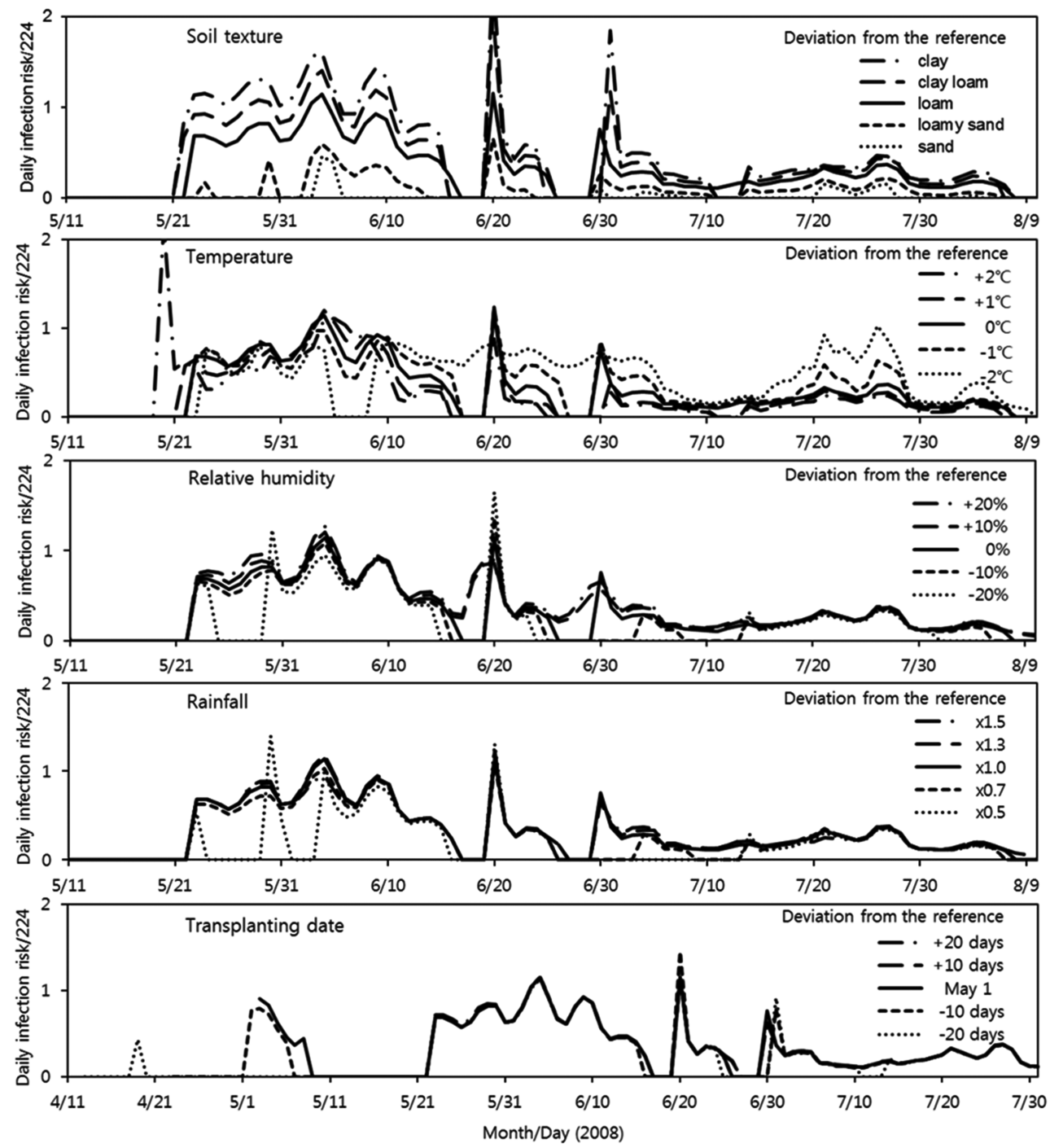

Fig. 7. Sensitivity of the infection risk model (eq. 10) to changes in soil texture, temperature, relative humidity, rainfall and transplanting date as compared with the reference conditions monitored at the chili pepper field in Suwon in 2008. The y-axis is the ratio of estimated daily infection risk to threshold infection risk of 224. 
plotted as compared with the response to the reference conditions which were monitored at the chili pepper field in Suwon in 2008 (Fig. 7). As for soil texture, clay showed the highest levels of infection risk and followed in order by clay loam, loam, loamy sand, and sand. The response of infection risk model to different soil textures was particularly apparent during the early season until June. The changes in temperature also affected the model output throughout the growing season. Temperature increase by $2{ }^{\circ} \mathrm{C}$ resulted in significant increase in infection risk at the early season in May. On the other hand, decrease in temperature by $2{ }^{\circ} \mathrm{C}$ caused noticeable changes in infection risk in June and afterward. Decrease in relative humidity and rainfall affected the model output especially during May and early June. Drastic changes in infection risk were noted during the period when relative humidity became decreased by $20 \%$ or only $50 \%$ of rainfall occurred as compared with the reference conditions at Suwon in 2008. Changes in the transplanting date of pepper seedlings showed little differences in daily infection risks from the reference response.

\section{Discussion}

An infection risk model for Phytophthora blight on chili pepper plants was developed to estimate the first date of disease occurrence after overwintering in the field. Various data and models on the epidemiology of Phytophthora capsici and the soil water content were adopted from the literature (Allen et al., 1998; Bernhardt and Grogan, 1982; Cronshey et al., 1986; Duniway, 1975; Erwin et al., 1983; Erwin and Ribeiro, 1996; Hasegawa et al., 2006; Hausbeck and Lamour, 2004; Hur, 2002; Jee et al., 2000; Jung, 2005; Jung et al., 2000; Katsura, 1971; Ponce and Hawkins, 1996). The infection risk model deals with the root infection process in soil, which is distinct from other disease forecast models determining possible infection on aerial parts of host plants based on temperature and wetness period (De Wolf and Isard, 2007; Magarey et al., 2005).

The infection risk model developed in this study consisted of three parts comprising estimation of the zoosporangium formation, the soil water content, and the amount of active inoculum in soil. The daily weather data on air temperature, relative humidity and rainfall and the soil texture data of local areas were used to estimate the daily infection risk that was quantified as the accumulated amount of active inoculum during the prior three days. In order to estimate the date of primary infection after overwintering, we proposed a threshold infection risk that may be high enough for the pathogen to cause infection on the host plant in the field. The threshold level of infection risk was determined by analyzing 190 data sets on weather and disease occurrence from 154 locations during 2001-2006.
To our knowledge, this is the first disease forecast model considering both weather conditions and soil water content to predict the primary infection of Phytophthora blight on pepper plants after overwintering.

The second order polynomial model in Fig. 1 describing effects of temperature on zoosporangium formation of Phytophthora capsici appeared well fitted to the data from laboratory experiments conducted in this study. However, variations in temperature response of zoosporangium formation are found in the literature. Although the temperature range for zoosporangium formation was $15-35^{\circ} \mathrm{C}$ in this study, Dvinagracia (1969) reported that it was $21-33^{\circ} \mathrm{C}$. It was also found that the temperature response of Phytophthora capsici may be slightly different from that of other Phytophthora spp. such as $P$. infestans, $P$. parasitica, $P$. palmivora, and P. lateralis (Brasier, 1969; Crosier, 1934; Englander and Roth, 1980; Wills, 1954). Therefore, the model describing effect of temperature on zoosporangium formation may need slight variations depending on isolates of Phytophthora spp.

Soil water content is a crucial factor for development of Phytophthora diseases (Hwang and Kim, 1995). However, soil water content data are often unavailable for local areas in Korea. A soil water content model was proposed in this study to estimate daily soil water content in pepper fields. The water balance model (Hasegawa et al., 2006; Jung et al., 2000) was simplified by ignoring the factors for irrigation and upward movement of water by capillary force. The assumptions adopted in this study regarding irrigation, drainage, and upward movement of soil water would be possible considering the cultural practices commonly used by pepper growers and the well-drained soil in most crop fields in Korea. The soil water content model estimated volumetric water content in soil based on the amount of water due to precipitation, runoff, drainage, and evapotranspiration. The KMA weather network with more than 627 automated weather stations over the South Korean Peninsula (Kang et al., 2010) and the digital soil texture map of Korea at the spatial resolution of $30 \mathrm{~m} \times 30 \mathrm{~m}$ (Hong et al., 2009) are the valuable sources of input data for estimating the daily soil water contents for local areas throughout Korea.

The soil temperature data at $30 \mathrm{~cm}$ depth under polyethylene film mulching are not available in the KMA weather network. The regression model in Fig. 2 appeared to describe appropriately the quantitative relationship between the daily mean air temperature at $120 \mathrm{~cm}$ above ground and the daily mean soil temperature at $30 \mathrm{~cm}$ depth below the top of raised beds covered with polyethylene film mulching at chili pepper fields. Application of the regression model is an alternative for generating soil temperature data that can be used for estimation of the daily soil water 
content and the infection risk of Phytophthora blight.

The comparison between the estimated and observed soil water contents in Fig. 3 suggested that the soil water content model (eq. 6) generally underestimated the amount of soil water in pepper fields. However, the model was responsive to rainfall resulting in peaks at rainfall and the model output followed the trend of temporal changes of the observed soil water contents for both Suwon and Andong. The similarity in the shape of temporal changes between the estimated and the observed soil water contents indicates that the soil water content model is capable of identifying the critical soil moisture conditions for disease development.

In this study, the infection risk was assumed to be a function of the amount of zoospores and germinated zoosporangia available for infecting roots of pepper plants in soil. The infection risk model (eq. 10) estimates the amount of active inoculum in soil based on the effects of temperature and soil water content on zoosporangium production, and differentiation of zoosporangia into direct germination or zoospore release. Survival of zoospores and germinated zoosporangia was also taken into consideration in the model.

The infection risk model in this study was set to accumulate zoospores and germinated zoosporangia produced during the prior three days and used the accumulated amount as the active inoculum for root infection. In an in vitro test using zoospore suspension, zoospores germinated quickly and only approximately $10 \%$ of zoospores appeared intact at 48 hours after their contact with pepper roots (Hur, 2002). In our study, zoospores of the pathogen in the field soil were assumed to remain infectious for 3 days after their release from zoosporangia. Granke and Hausbeck (2010) reported that 5-day old zoospores of Phytophthora capsici in aqueous solution could survive and initiate infection on cucumber fruits when the zoospore density was greater than $5 \times 10^{3}$ zoospores $/ \mathrm{ml}$, whereas fruits were infected by only 3-, 1-, and 0-day old zoospores when their density was $1 \times$ $10^{3}$ zoospores $/ \mathrm{ml}$. Their results suggested that inoculum density in soil may have affected infectivity of zoospores in aqueous solution and zoospores were able to infect host plants only for 2-3 days when the inoculum density is less than $1 \times 10^{3}$ zoospores $/ \mathrm{ml}$. Under the crop field conditions, the primary inoculum density in soil after overwintering is probably quite low. Jee et al. (2000) found that the inoculum density of Phytophthora spp. in soil was 10-22 propagules/ $\mathrm{g}$ soil in pepper and tomato fields where Phytophthora blight had occurred in the previous year, and it was less than 0.5 propagules/g soil if the disease had never occurred in the field previously. Consequently, the 3-day accumulation of zoospores for root infection in the infection risk model is probably a reasonable assumption reflecting the situation happening in pepper fields.

The threshold infection risk in this study was defined as the estimated level of daily infection risk that may be high enough for the pathogen to cause infections on pepper plants in the field. Therefore, the primary infection could be expected when the estimated daily infection risk reaches the threshold level for the first time after overwintering in the field. Using the 190 data sets on the difference in days (DIF) between the estimated dates of primary infection and the observation dates of first disease occurrence at 156 locations during 2001-2006 (Fig. 4), we have found that the daily infection risk of 224 would be most suitable for predicting possible initiation of Phytophthora blight development on chili peppers in the field. The normal distribution of relative frequency of DIF in Fig. 5 also confirms the aptness of the threshold infection risk of 224 for all of 190 cases of Phytophthora blight epidemics.

With the threshold infection risk of 224, the analysis on the 190 cases of Phytophthora blight epidemics suggested that the average incubation period is probably $8 \pm 3$ days between the primary infection and the first disease occurrence under natural conditions in Korea. Kim et al. (1989), Kim et al. (2008) and Sang et al. (2008) reported that it has taken 5-7 days until the symptom appearance of Phytophthora blight of peppers in the field plots when 9 10-week old pepper seedlings were inoculated with zoospore suspension $\left(10^{4} \sim 10^{5}\right.$ zoospores $\left./ \mathrm{ml}\right)$ by soil drenching around individual plants. Considering the favorable conditions for artificial inoculation in their experiments, the average incubation period of $8 \pm 3$ days as suggested by the infection risk model would be a plausible time period between the primary infection and the first occurrence of disease symptoms for Phytophthora blight epidemics occurring under natural conditions in the field.

In the validation test, the infection risk model was found to be relatively accurate in predicting the dates of first disease occurrence (Table 1). For the five cases at Suwon, Hwaseong, and Taean, the observed dates of first disease occurrence after overwintering were within the $95 \%$ confidence interval of the expected dates. The weather conditions at Bonghwa in 2009 were relatively unfavorable for Phytophthora blight, and consequently the infection risk estimated by the model had never reached as high as 224 throughout the growing season. However, the first occurrence of disease at Bonghwa on June 20 may have been caused by the possible primary infection when the infection risk reached a peak of 206.4 on June 12. Although 190 data sets from 156 locations were used in this study to determine the threshold infection risk of 224, further investigation is yet to be conducted to find the ideal threshold levels of infection risk that can be applied to different locations with various environmental conditions.

Sensitivity analysis involves changing the values of rates, variables and initial conditions in the model to determine 
their contribution to the behavior of the model (Zadoks and Rabbinge, 1985). In this study, the sensitivity analysis on the infection risk model showed the relative importance of input variables (Fig. 7). Of the factors tested for the sensitivity of the infection risk model, changes in soil texture and temperature made significant contribution to the behavior of the model throughout the growing season. Soil texture affects the water holding capacity of soil, and increased clay content increases total water retention (Brady, 1990). The increased infection risk in clayey soils was due to the fact that higher water content in more clayey soils than in less clayey soils provided favorable conditions for Phytophthora blight development. The sensitive response of the infection risk model to soil texture resulted from the soil water content model (eq. 6) that is capable of identifying the critical soil moisture conditions for disease development. The differences between soil types in infection risk were particularly apparent during the early season. This was caused by the relatively dry weather conditions during May. Consequently, if other environmental conditions are the same, the infection risk model would expect earlier development of Phytophthora blight in clayey soils than in loamy or sandy soils after overwintering. Since soil texture affected the infection risk throughout the growing season, disease incidence of Phytophthora blight may also be higher in more clayey soils than in less clayey soils as often noticed in pepper fields with poor drainage (Larkin et al., 1995; Ristaino et al., 1993).

The temperature response of the infection risk model reflected the effects of temperature on the production and differentiation of zoosporangia. During the period of May 11-20, 2008, the average daily temperature in Suwon was $14.8^{\circ} \mathrm{C}$. Therefore, increase by $2^{\circ} \mathrm{C}$ resulted in temperature conditions of higher than $15^{\circ} \mathrm{C}$ at which the pathogen was able to produce zoosporangia. The sudden increase in infection risk in May resulted from the temperature increase by $2^{\circ} \mathrm{C}$. Afterward, the temperature in Suwon was warm enough for zoosporangium production and the temperature increase by $1^{\circ} \mathrm{C}$ or $2^{\circ} \mathrm{C}$ did not cause much change in infection risk as compared with the response to the reference conditions monitored at the chili pepper field in Suwon in 2008. As for the cases of temperature decrease by $1^{\circ} \mathrm{C}$ or $2^{\circ} \mathrm{C}$, increase in infection risk during the summer from mid-June to August was due to increase in the proportion of zoosporangia that were differentiated into zoospores. According to eq. 7, the proportion of zoosporangia releasing zoospores decreases as temperature increases and meanwhile more zoosporangia germinate directly. Therefore, the temperature decrease by $1^{\circ} \mathrm{C}$ or $2^{\circ} \mathrm{C}$ during summer provided more favorable conditions for zoospore production in soil, resulting in higher infection risk than the reference conditions in Suwon in 2008. The temperature decrease also caused decrease in infection risk especially early in the growing season. On June 5 and 6 , 2008 at the pepper field in Suwon, temperature was $15.8^{\circ} \mathrm{C}$ and $16.9^{\circ} \mathrm{C}$, respectively. If temperature decreased by $2{ }^{\circ} \mathrm{C}$ on those days, the temperature condition was too low for the pathogen to produce zoosporangia and a drastic decrease in infection risk in early June was predicted by the infection risk model.

Relative humidity and rainfall did not affect as much as temperature and soil texture on the behavior of the infection risk model. In the soil water content model (eq. 6), relative humidity is needed to calculate the water loss from soil due to evapotranspiration. Consequently, relative humidity and rainfall influence the amount of active inoculum in soil by affecting the water balance in soil. In this study, it was found that the effect of relative humidity and rainfall on the model output was particularly apparent under the relatively dry conditions in May. When relative humidity was decreased by $20 \%$ or only $50 \%$ of rainfall occurred as compared with the reference conditions in Suwon in 2008, the accumulation of zoosporangia in soil was expected by the infection risk model without direct germination or zoospore release in late May, and then a rainfall of $37 \mathrm{~mm}$ on May 28 probably triggered direct germination or zoospore release of accumulated zoosporangia, resulting in the drastic increase in estimated infection risk on May 30. For other cases of changes in relative humidity and rainfall in Fig. 7, zoosporangia in soil had been likely to keep germinating to some extent via zoospores or germ tube during May, and the rainfall on May 28 did not affected the estimated infection risk as much as in the cases of decrease in relative humidity by $20 \%$ or $50 \%$ reduction of rainfall.

The sensitivity analysis of the infection risk model showed the importance of temperature and soil water content in the behavior of the model, which is in agreement with the epidemiology of Phytophthora diseases (Caf-Filho and Duniway, 1995; Hausbeck and Lamour, 2004; Kim et al., 1985; Ristaino and Johnston, 1999). Temperature data are often easily available from a public weather monitoring system, whereas it is not easy to obtain soil water content data for local crop fields. In order to estimate daily soil water content, we have developed a soil water content model by modifying the soil water balance model in the literature (Hasegawa et al., 2006; Jung et al., 2000). The soil water content model was found to be responsive to rainfall and capable of identifying the critical soil moisture conditions for disease development. On the other hand, the model has a problem of underestimating soil water content as was shown in Fig. 3, and this leads to underestimation of infection risk by the infection risk model. However, the underestimation of soil water content would not be a serious drawback in determining the primary infection date 
of the pathogen as long as the soil water content model is able to identify the critical soil moisture conditions for disease development. The problem due to the underestimation of soil water content can be negated by adjusting the threshold level of infection risk.

In the infection risk model (eq. 10), the infection risk is defined as the amount of the active inoculum accumulated for the prior three days. The active inoculum in this study includes zoospores and directly germinated zoosporangia being capable of infecting host plants. Since the amount of active inoculum is affected by environmental factors such as temperature and soil water content, the infection risk in this study may be conceptually similar to the inoculum potential that was defined as inoculum density being modified by capacity (or environmental) factors (Baker, 1978). The inoculum potential was quantified in various manners and applied to comparative analyses of epidemics (Bashi et al., 1982; Geypens, 1974; Lockwood, 1988; Stack, 1989). The concept of infection risk also could be applied to study comparative epidemiology of diseases caused by Phytophthora spp. Further studies on quantitative relationships of the infection risk with inoculum density in soil and disease incidence are needed for better understanding of epidemiology of Phytophthora blight of pepper.

In conclusion, the infection risk model was found to be valid in determining the primary infection date of Phytophthora blight of chili pepper in Korea using weather data including daily temperature, relative humidity and rainfall, and soil texture data. With the threshold infection risk of 224 , the model was able to forecast the first occurrence of the disease in the field approximately $8 \pm 3$ days prior to the actual disease development. The $8 \pm 3$-day forecast would be useful for pepper growers to implement fungicide applications in order to prevent initiation of Phytophthora blight development in the early growing season after overwintering. Further evaluation on the infection risk model along with fungicide spray programs is needed for practical use of the infection risk model by pepper growers.

\section{Acknowledgments}

This work was supported by the Special Agriculture Program (Project Numbers: PJ001468 and PJ004582) from the Rural Development Administration, Republic of Korea.

\section{References}

Allen, R. G., Pereira, L. S., Raes, D. and Smith, M. 1998. Crop evapotranspiration: Guidelines for computing crop water requirements-irrigation and drainage paper No. 56. United Nations FAO, Rome, Italy. 326 pp.

Baker, R. 1978. Inoculum potential. In: Plant disease. An advanced treatise, vol. 2., ed. by J. G. Horsfall and E. B. Cowling, pp.
137-156. Academic Press, New York, USA.

Bashi, E., Ben-Joseph, Y. and Rotem, J. 1982. Inoculum potential of Phytophthora infestans and the development of potato late blight epidemics. Phytopathology 72:1043-1047.

Bernhardt, E. A. and Grogan, R. G. 1982. Effect of soil matric potential on the formation and indirect germination of sporangia of Phytophthora parasitica, Phytophthora capsici, and Phytophthora cryptogea. Phytopathology 72:507-511.

Bowers, J. H. and Mitchell, D. J. 1990. Effect of soil-water matric potential and periodic flooding on the mortality of pepper caused by Phytophthora capsici. Phytopathology 80:14471450.

Bowers, J. H. and Mitchell, D. J. 1991. Relationship between inoculum level of Phytophthora capsici and mortality of pepper. Phytopathology 81:178-184.

Bowers, J. H., Papavizas, G. C. and Johnston, S. A. 1990. Effect of soil temperature and soil water matric potential on the survival of Phytophthora capsici in natural soil. Plant Dis. 74:771-777.

Brady, N. C. 1990. The nature and properties of soils, $10^{\text {th }} \mathrm{ed}$. Macmillan Publishing Company, New York, USA. 621 pp.

Brasier, C. M. 1969. The effect of light and temperature on reproduction in vitro in two tropical species of Phytophthora. Trans. Br. Mycol. Soc. 52:105-113.

Caf-Filho, A. C. and Duniway, J. M. 1995. Effects of furrow irrigation schedules and host genotype on Phytophthora root rot of pepper. Plant Dis. 79:39-43.

Campbell, G. S. 1985. Soil Physics with BASIC: Transport Models for Soil-Plant Systems. Elsevier, Amsterdam, Netherlands. 150 pp.

Cronshey, R., McCuen, R. H., Miller, N., Rawls, W., Robbins, S., and Woodward, D. 1986. Urban hydrology for small watersheds. National Resources Conservation Service, USDA, Washington, DC, USA. 160 pp.

Crosier, W. 1934. Studies in the biology of Phytophthora infestans de Bary. Cornell Univ. Agric. Exp. Stn. Mem. 155. Cornell University, Ithaca, USA. 40 pp.

De Wolf, E. D. and Isard, S. A. 2007. Disease cycle approach to plant disease prediction. Annu. Rev. Phytopathol. 45:203-220.

Duniway, J. M. 1975. Limiting influence of low water potential on formation of sporangia by Phytophthora drechsleri in soil. Phytopathology 65:1089-1093.

Duniway, J. M. 1976. Movement of zoospores of Phytophthora cryptogea in soil of various textures and matric potentials. Phytopathology 66:877-882.

Duniway, J. M. 1979. Water relations of water molds. Annu. Rev. Phytopathol. 17:431-460.

Dvinagracia, G. G. 1969. Sporangial and oospore formation by Phytophthora capsici. Philipp. Agric. 53:148-165.

Englander, L. and Roth, L. F. 1980. Interaction of light and sterol on sporangium and chlamydospore production by Phytophthora lateralis. Phytopathology 70:650-654.

Erwin, D. C., Bartnicki-Garcia, S. and Tsao, P. H. 1983. Phytophthora: Its biology, taxonomy, ecology, and pathology. American Phytopathology Society, St. Paul, Minnesota, USA. 392 pp.

Erwin, D. C. and Ribeiro, O. K. 1996. Phytophthora diseases worldwide. APS Press, St. Paul, Minnesota, USA. 592 pp. 
Geypens, M. 1974. Inoculum potential of soil-borne plant pathogenic fungi: Problems encountered in analysis and significance in epidemiology. Agro-Ecosystems 1:177-192.

Granke, L. L. and Hausbeck, M. K. 2010. Effects of temperature, concentration, age, and algaecides on Phytophthora capsici zoospore infectivity. Plant Dis. 94:54-60.

Hasegawa, S., Kasubuchi, T. and Miyazaki, T. 2006. Water regimes in fields with vegetation. In: Water flow in soils, ed. by $\mathrm{T}$. Miyazaki, pp. 301-350. CRC Press, Boca Raton, FL., USA.

Hausbeck, M. K. and Lamour, K. H. 2004. Phytophthora capsici on vegetable crops: Research progress and management challenges. Plant Dis. 88:1292-1303.

Hong, S. Y., Zhang, Y. S., Hyun, B. K., Sonn, K. Y., Kim, Y. H., Jung, S. J., Park, C. W., Song, K. C., Jang, B. C., Choe, E. Y., Lee, Y. J., Ha, S. K., Kim, M. S., Lee, J. S., Jung, G. B., Ko, B. G. and Kim, G. Y. 2009. An introduction of Korean soil information system. Kor. J. Soil Sci. Fert. (in Korean) 42:21-28.

Hord, M. J. and Ristaino, J. B. 1992. Effect of the matric component of soil water potential on infection of pepper seedlings in soil infested with oospores of Phytophthora capsici. Phytopathology 82:792-798.

Hur, Y. S. 2002. In vivo study of infection process and development of stem and root rot disease in Capsicum annuum by fungal pathogen Phytophthora capsici L. MS. thesis. Seoul National University, Seoul, Korea.

Hwang, B. K. and Kim, B. S. 1995. In-vivo efficacy and in-vitro activity of tubercidin, an antibiotic nucleoside, for control of Phytophthora capsici blight in Capsicum annuum. Pestic. Sci. 44:255-260.

Hwang, E. H. and Lee, S. G. 2001. A forecasting model of Phytophthora blight incidence in red pepper and its computer system. Kor. J. Agric. Forest Meteorol. (in Korean) 3:16-21.

Jee, H. J., Cho, W. D. and Kim, C. H. 2000. Phytophthora diseases in Korea. National Institute of Agricultural Science and Technology, Suwon, Korea. 226 pp.

Jung, H. W. 2005. Estimation of crop water requirement in Korea. College of Agriculture and Life Sciences, Seoul National University, Seoul, Korea. 168 pp.

Jung, H. W., Park, S. H., Lee, N. H., Kim, S. J., Choi, J. Y. and Park, G. U. 2000. Computer model for irrigation and drainage. Seonggyunsa, Seoul, Korea. 254 pp.

Kang, H. J., Jeong, K. H., Ann, K. S., Han, C. U., Kim, S. H. and Kim, Y. G. 2011. Damage analysis and estimation of control thresholds for Phytophthora blight of hot pepper (Capsicum annuum). Res. Plant Dis. (in Korean) 17:1-12.

Kang, W. S., Hong, S. S., Han, Y. K., Kim, K. R., Kim, S. G. and Park, E. W. 2010. A web-based information system for plant disease forecast based on weather data at high spatial resolution. Plant Pathol. J. 26:37-48.

Katsura, K. 1971. Some ecological studies on zoospore of Phytophthora capsici Leonian. Rev. Plant Prot. Res. 4:58-70.

Kim, G. S., Park, C. S. and Choi, J. S. 1985. Effects of inoculum density, plant age and temperature on the incidence of crown rot of pepper caused by Phytophthora capsici. Kor. J. Plant Prot. (in Korean) 24:117-121.

Kim, H. S., Sang, M. K., Jeun, Y. C., Hwang, B. K. and Kim, K.
D. 2008. Sequential selection and efficacy of antagonistic rhizobacteria for controlling Phytophthora blight of pepper. Crop Prot. 27:463-443.

Kim, Y. J., Hwang, B. K. and Park, K. W. 1989. Expression of age-related resistance in pepper plants infected with Phytophthora capsici. Plant Dis. 73:745-747.

Kreutzer, W. A., Bodine, E. W. and Durrell, L. W. 1940. Cucurbit diseases and rot of tomato fruit caused by Phytophthora capsici. Phytopathology 30:972-976.

Larkin, R. P., Gumpertz, M. L. and Ristaino, J. B. 1995. Geostatistical analysis of Phytophthora epidemic development in commercial bell pepper fields. Phytopathology 85:191-203.

Lockwood, J. L. 1988. Evolution of concepts associated with soilborne plant pathogens. Annu. Rev. Phytopathol. 26:93-121.

Magarey, R. D., Sutton, T. B. and Thayer, C. L. 2005. A simple generic infection model for foliar fungal plant pathogens. Phytopathology 95:92-100.

Ponce, V. M. and Hawkins, R. H. 1996. Runoff curve number: Has it reached maturity? J. Hydrol. Eng. 1:11-19.

Ristaino, J. B. and Johnston, S. A. 1999. Ecological based approaches to management of Phytophthora blight on bell pepper. Plant Dis. 80:1080-1089.

Ristaino, J. B., Larkin, R. P. and Campbell, C. L. 1993. Spatial and temporal dynamics of Phytophthora capsici in commercial bell pepper fields. Phytopathology 83:1312-1320.

Rohlf, F. J. and Sokal, R. R. 1969. Statistical Tables. W. H. Freeman and Company, San Francisco, USA. 253 pp.

Sang, M. K., Chun, S. C. and Kim, K. D. 2008. Biological control of Phytophthora blight of pepper by antagonistic rhizobacteria selected from a sequential screening procedure. Biol. Cont. 46:424-433.

SAS Institute Inc. 2011a. Base SAS 9.3 Procedure Guide: Statistical Procedures. Cary, NC: SAS Institute Inc.

SAS Institute Inc. 2011b. SAS/STAT 9.3 User's Guide. Cary, NC: SAS Institute Inc.

Shapiro, S. S. and Wilk, M. B. 1965. An analysis of variance test for normality (complete samples). Biometrika 52:591-611.

Shiozawa, S. and Campbell, G. S. 1991. On the calculation of mean particle diameter and standard deviation from sand, silt, and clay fractions. Soil Sci. 152:427-431.

Singh, V. P. 1988. Hydrologic systems, vol. 2. Watershed modeling. Prentice Hall, Englewood Cliffs, New Jersey, USA. 448 pp.

Stack, R. W. 1989. A comparison of the inoculum potential of ascospores and conidia of Gibberella zeae. Can. J. Plant Pathol. 11:137-142.

Wills, W. H. 1954. Sporangium formation of Phytophthora parasitica Dastur var. nicotianae (Breda de Hann) Tucker. J. Elisha Mitchell Sci. Soc. 70:235-243.

Yun, J. I., Yi, D. S., Choi, S. I., Park, E. W. and Hwang, H. 1999. Elevation-corrected spatial interpolation for near-real time generation of meteorological surfaces from point observations. AgroInformatics J. (in Korean) 1:28-33.

Zadoks, J. C. and Rabbinge, R. 1985. Modeling to a purpose. In: Advances in plant pathology, vol. 3. Mathematical modelling of crop disease, ed. by G. A. Gilligan, pp. 231-244. Academic Press, Orlando, USA. 